\title{
AGGRESSIVE ANGIOMYXOMA: A RARE SOFT TISSUE TUMOR
}

Ritu Sharma1, Sunny Goyal², Apoorva Sarawat ${ }^{3}$, H. B. Saxena ${ }^{4}$, Nikhil Bansal ${ }^{5}$

\section{HOW TO CITE THIS ARTICLE:}

Ritu Sharma, Sunny Goyal, Apoorva Sarawat, H. B. Saxena, Nikhil Bansal5 "Aggressive Angiomyxoma: A Rare Soft Tissue Tumor". Journal of Evolution of Medical and Dental Sciences 2015; Vol. 4, Issue 02, January 05;

Page: 303-307, DOI: 10.14260/jemds/2015/47

\begin{abstract}
Introduction-Aggerssive angiomyxoma is a rare soft tissue tumor, typically occuring in the female pelvis and carrying a high risk of local infiltration and relapse. Surgery remains the first line of treatment. ${ }^{1}$ Material and Methods- We describe a case of perineal mass in a 20 -year old woman who underwent surgical excision of the tumor. Diagnosis was made on the histopathological examination and positive immunohistochemical staining with estrogen and progesterone receptors in Pathology department of Mahatma Gandhi Medical College \& Hospital, Jaipur. Discussion: Almost exclusively, AAM involves women of childbearing age; although very rare cases have been diagnosed in perimenopausal women. ${ }^{1}$ It usually exhibit a slow, insidious growth pattern, a capacity for local infiltration and a marked tendency to repeated local recurrence. Preoperative diagnosis of AAM is often difficult because of its rarity. Misdiagnosis is common, occurring in $>80 \%$ of cases. ${ }^{2}$ Histopathologically, differentiation may be difficult between the following: Liposarcoma, myxoma; myxoid neurofibroma. ${ }^{3}$ The methods to establish a final diagnosis is pathological analysis and immunohistochemical stain.Background: Aggressive anigomyxoma is rare mesenchymal tumor that affects women in more than $90 \%$ of cases. ${ }^{4}$ It is most commonly arises in the vulvovaginal region, region. Other sites in womens are perineum, pelvis, buttock and retroperitoneum. ${ }^{1}$ The term aggressive emphasizes the often infiltrative nature of the tumor and its frequent association with local recurrence. ${ }^{5}$
\end{abstract}

CASE REPORT: A 25 year old woman, presented with a complain of swelling in perineal region since 8-9 months.

CLINICAL PRESENTATION: Patient presents with pelvic fullness and with a visible perineal or vulval mass that is discovered during routine pelvic examination or with radiographic imaging. No significant past history present.

ON EXAMINATION: General examination only pallor present. Systemic examination: Large mass measuring $22 \times 10 \times 10 \mathrm{~cm}$ is present in perineal region. Biochemical examination: Normal.

RADIOLOGIC FEATURES: Well-defined, homogeneous mass that is hypodense relative to muscle, or it may be predominantly cystic with solid components. Characteristic appearances. On CECT include hypointensity on T1- weighted images and hyperintensity on T2-weighted images.

MRI OF PELVIS (PLAIN AND CONTRAST): Shows $20 \times 10$ x 9.2cm sized (CCx AP x Tr), large, well marginated, lobulated, heterogeneously enhancing mass lesion with central non-enhancing / necrotic area seen in per- sacral region / pelvis with extent as described above. Findings S/o Neoplastic mass lesion. 


\section{CASE REPORT}
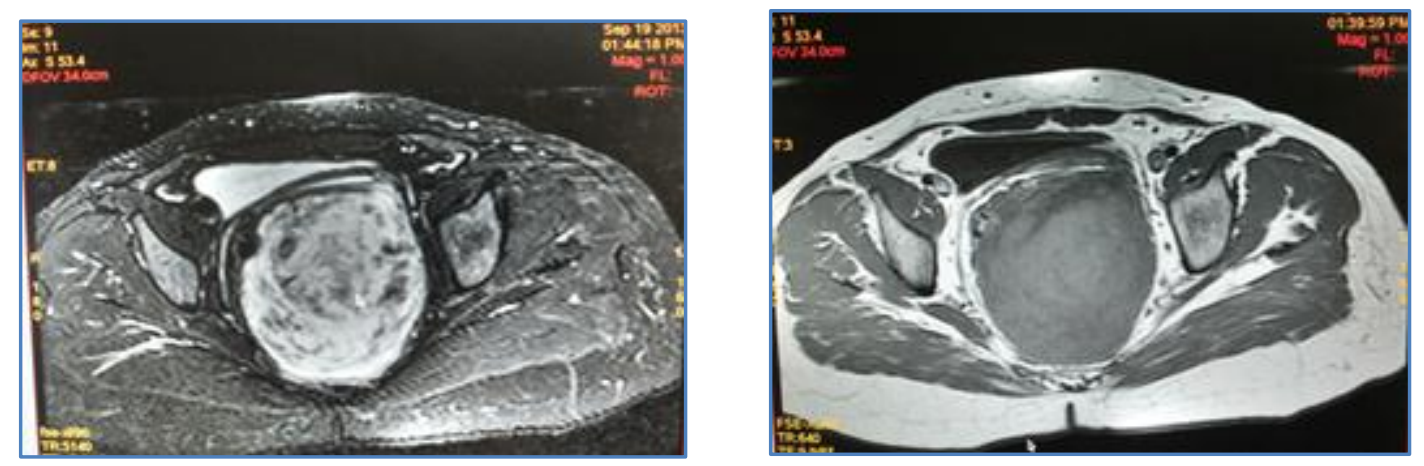

MRI of Pelvis axial view
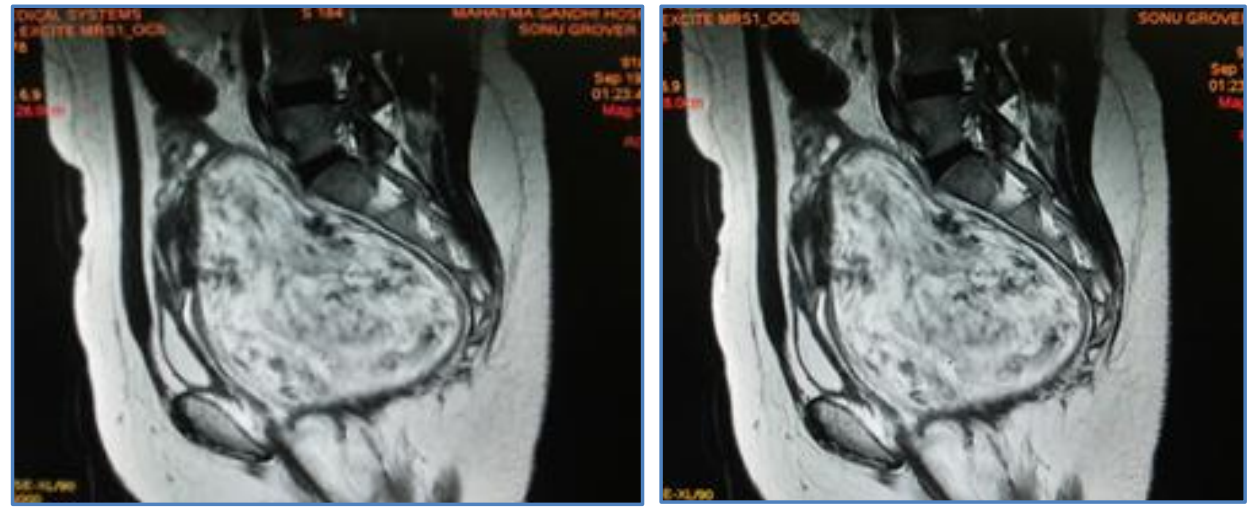

MRI of Pelvis sagittal view

PATHOLOGIC FEATURES: GROSS FEATURES -Formalin fixed specimen consist Grey-white to Greybrown, non-encapsulated, oval to rounded mass measures $20 \times 9 \times 9 \mathrm{~cm}$ in size, soft to rubbery in consistency with a glistening, pink or reddish-tan external surface. Cut surface is gelatinous, homogenous gray-white with focal areas of hemorrhage seen.

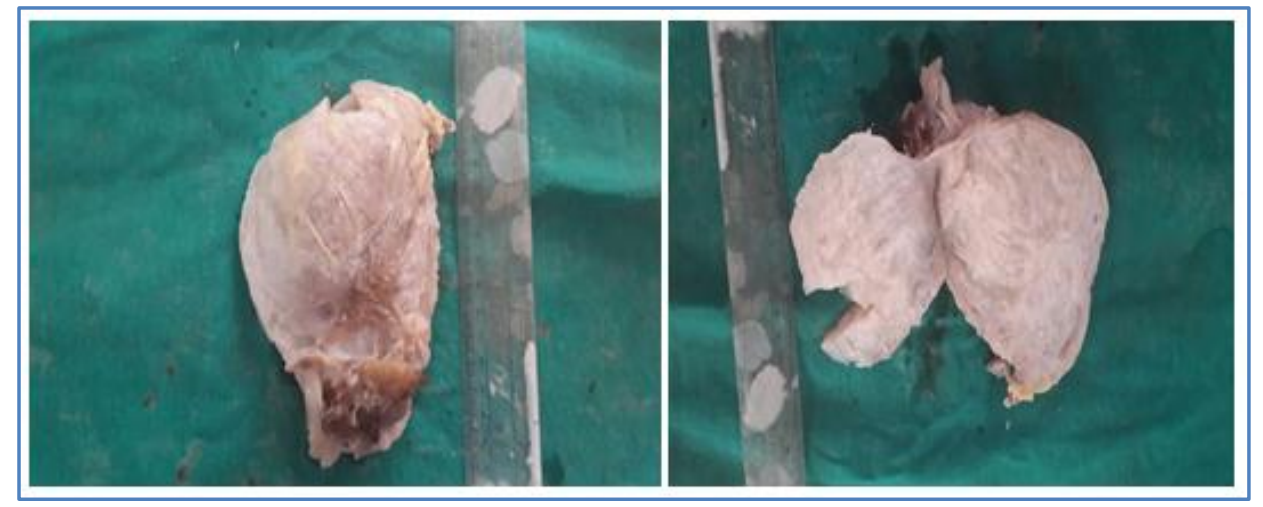

FIGURE SHOWING: Glistening, pink or reddish-tan external surface 


\section{CASE REPORT}

MICROSCOPIC FEATURES: $\mathrm{H}$ and E section studied shows sparsely cellular tumor composed of pale to eosinophilic stroma studded with numerous haphazardly arranged blood vessels that stand out against the myxoid background and range in size from thin walled capillaries and venules to large muscular arteries. Paucicellular neoplasm with large areas of myxoid stroma with no necrosis is seen and very scanty mitotic activity. Overall histomorphology suggestive of: AGRRESSIVE ANGIOMYXOMA.
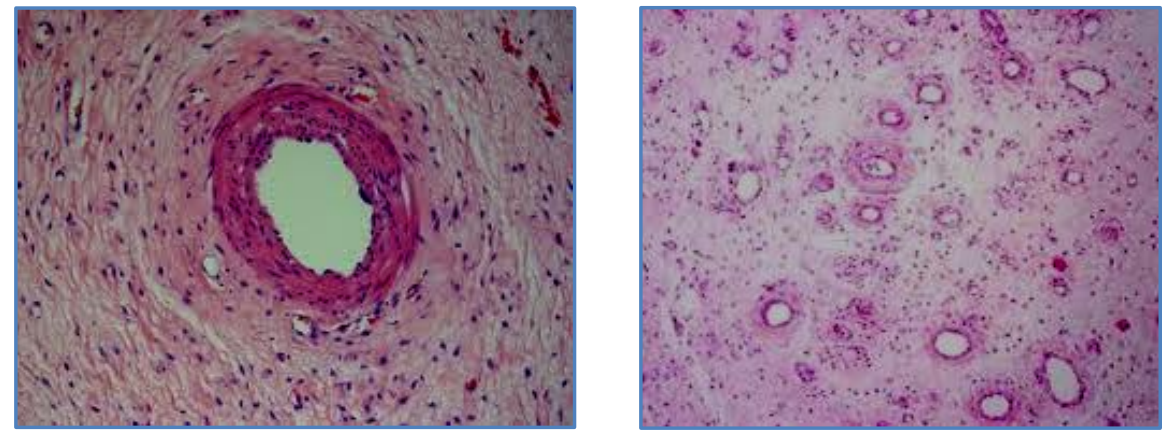

\section{AGRRESSIVE ANGIOMYXOMA}

IMMUNOHISTOCHEMICAL FEATURES: The tumor shows diffuse immune-positivity for vimentin and desmin. Smooth muscle actin highlights myoid bundles and may be positive in individual tumor cells. S100 reactivity is not a feature of aggressive angiomyxoma.

\begin{tabular}{|ll|c|}
\hline & MARKER & PRESENT /ABSENT \\
\hline 1. & Desmin (DE-R-11) & Present \\
\hline 2. & Vimentin & Present \\
\hline 3. & SMA & Present \\
\hline 4. & Progestron receptor & Present \\
\hline 5. & S-100 & Absent \\
\hline
\end{tabular}
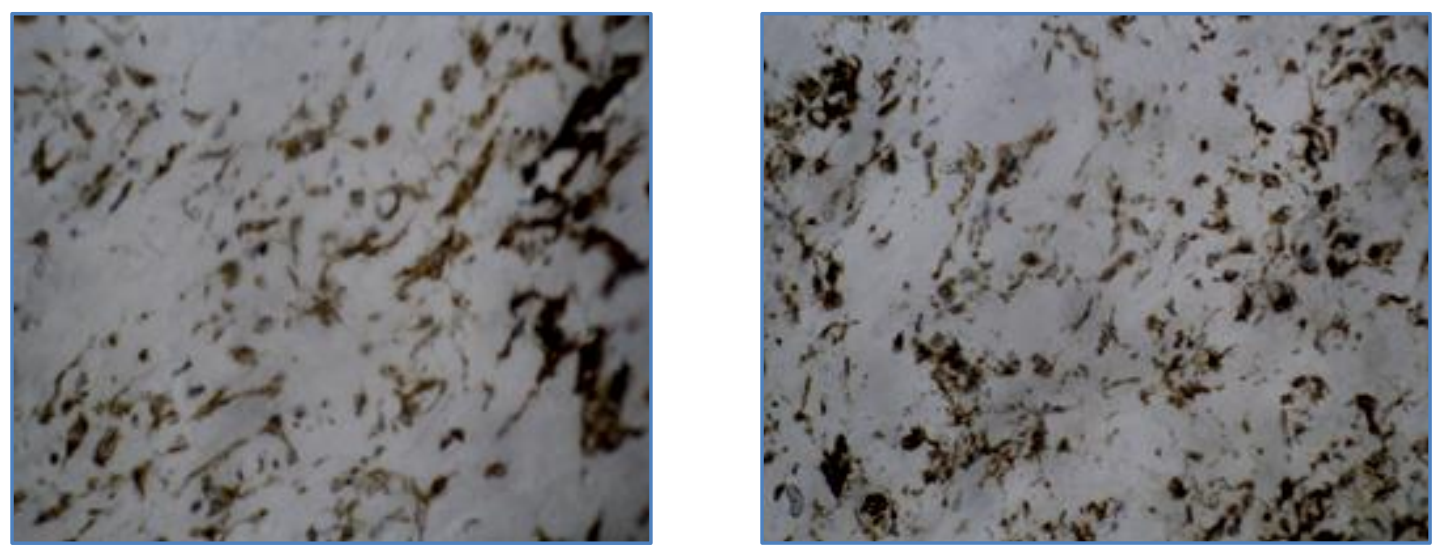

Desmin positivity Vimentin positivity 

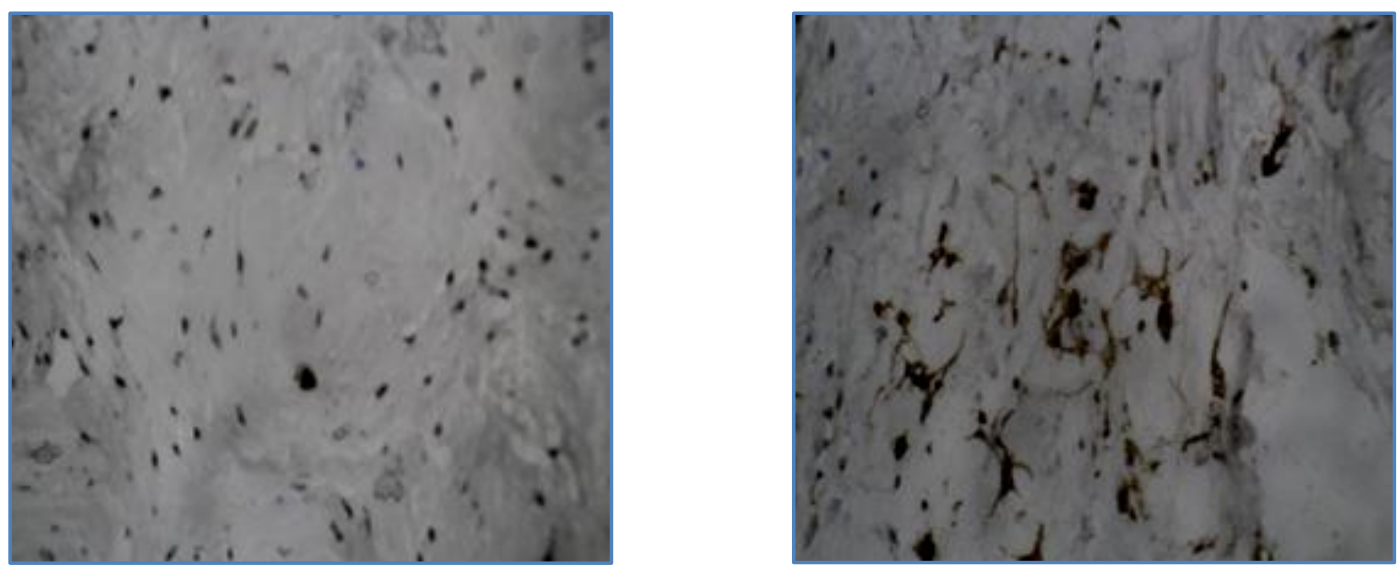

Progesteron positivity Smooth Muscle Actin (SMA)

DISCUSSION: Steeper and Rosai ${ }^{6}$ first reported nine cases of pelvic neoplasm, describe as AAM in 1983.The term is now widely accepted and, in 2003 was classified by the WHO as deep angiomyxoma. ${ }^{7}$ The pathogensis of AAM is not clear. Studies have demonstrated a translocation at the level of chromosome 12 with a consequent aberrant expression of the high mobility group protein isoform I -C involved in DNA transcription. ${ }^{1}$ Almost exclusively, AAM involves women of childbearing age, very rare cases have been diagnosed in perimenopausal women; a ratio of 6:1 (females: males) has been reported. ${ }^{1}$ Term "Aggressive" emphasizes the often infiltrative nature of the tumor and its frequent association with local recurrence. 5 The majority of the tumors were $>10$ centimeters in greatest dimension. Histological examination generally shows stellate and spindled-shaped neoplastic cells scattered in a background of loosely myxoid stroma with numerous blood vessels of varying caliber. The stromal cells can show immunoreactivity to different combinations of vimentin, desmin, smooth muscle actin ER and PR8. ${ }^{8}$

CONCLUSION: Aggressive angiomyxoma is a distinctive, locally aggressive, mesenchymal tumor that apperars to be relatively site specific and has a peak incidence in females in the fourth decade of life.

There is a strong propensity for local recurrence but meta disease has not been reported. 8 Detailed radiological examination is helpful in suspecting the problem, but histology is gold standard for diagnosis. Wide excision is curative and prognosis of such tumor is good. ${ }^{9}$

\section{REFERENCES:}

1. NX Sun and W Li. Aggressive Angiomyxoma of the vulva: Case report and literature review. Journal of International Medical Research 2010, 38: 1547.

2. Smith $\mathrm{OH}$, Worrell RV, Smith AY, et al: Aggressive angiomyxoma of the female pelvis and perineum: review of the literature. Gynecol Oncol 1991; 42: 79-85.

3. Behranwala A, Thomas JM: Aggressive angiomyxoma in females: is radical resection the only option. Acta Obstet Gynecol Scand 2000; 79: 216-220.

4. Eric K. Outwater, Barry E. Marchetto, Evan S. Siegelman et al. Aggressive Angiomyxoma: Findings on CT and MR imaging.AJR 1999; 172: 435-438.

5. Brian J. Sutton, MD; Jennifer Laudadio, MD. Aggressive Angiomyxoma. Arch Pathol lab Med.2012; 136: 217-221; 


\section{CASE REPORT}

6. Steeper TA, Rosai J: Aggressive Angiomyxoma of the female pelvis and perineum. Report of nine cases of a distinctive type of gynecologic soft-tissue neoplasm. Am J Surg Pathol 1983; 7: 463-475.

7. Tavassoli FA, Devilee P: Pathology and Genetics: Tumors of the Breast and Female Genital Organs. World Health Organization Classification of Tumors. Lyon: IARC Press, 2003;p 329.

8. John F. Fetsh, William B. Laskin, Martin Lefkowitz et al. Aggressive angiomyxoma. A clinicopathological study of 29 Female patients. American Cancer Society 1996/Vol 78/Number 1.

9. Sanjiv Kumar et al. Cases journal 2008, 1:131; doi: 10.1186/1757-1626-1-131. Aggressive angiomyxoma presenting with huge abdominal lump:A case report.

\section{AUTHORS:}

1. Ritu Sharma

2. Sunny Goyal

3. Apoorva Sarawat

4. H. B. Saxena

5. Nikhil Bansal

\section{PARTICULARS OF CONTRIBUTORS:}

1. Resident, Department of Pathology, Mahatma Gandhi Medical College and Hospital, Sitapura, Jaipur.

2. Resident, Department of Radiodiagnosis, Mahatma Gandhi Medical College and Hospital, Sitapura, Jaipur.

3. Resident, Department of Pathology, Mahatma Gandhi Medical College and Hospital, Sitapura, Jaipur.
4. Professor, Department of Pathology, Mahatma Gandhi Medical College and Hospital, Sitapura, Jaipur.

5. Resident, Department of Radiodiagnosis, Mahatma Gandhi Medical College and Hospital, Sitapura, Jaipur

\section{NAME ADDRESS EMAIL ID OF THE} CORRESPONDING AUTHOR:

Dr. Ritu Sharma,

Department of Pathology,

MGMCH, Jaipur.

E-mail: drritzsharma@gmail.com

Date of Submission: $13 / 11 / 2014$.

Date of Peer Review: 14/11/2014.

Date of Acceptance: 29/12/2014.

Date of Publishing: 05/01/2015. 